\section{Cureus}

\title{
Does Hemodynamic-Guided Heart Failure Management Reduce Hospitalization? A Systematic Review
}

\author{
Abdul M. Minhas ${ }^{1}$, Saba Ahmed ${ }^{2}$, Muhammad S. Khan ${ }^{3}$, Kaneez Fatima ${ }^{4}$, Muhammad N. \\ Anwar ${ }^{1}$, Jonathan Constantin ${ }^{5}$ \\ 1. Internal Medicine, Orange Park Medical Center 2. Medical Student, Dow University of Health Sciences \\ (DUHS), Karachi, Pakistan 3. Internal Medicine, John H Stroger J. Hospital of Cook County 4. Department \\ of Internal Medicine, Dow University of Health Sciences (DUHS), Karachi, Pakistan 5. Cardiology, Orange \\ Park Medical Center
}

$\square$ Corresponding author: Abdul M. Minhas, abdulmannan331@hotmail.com Disclosures can be found in Additional Information at the end of the article

\section{Abstract}

Heart failure (HF) is a pressing health concern as the expense of hospitalization financially burdens the health care system. Hemodynamic monitoring has the potential to detect increases in intracardiac filling pressures weeks before clinical deterioration; hence, preliminary findings of volume overload with the use of these devices may prevent the progression of disease and lead to a reduction in HF-associated hospitalizations. We extensively searched PubMed, Ovid SP, Embase, and Cochrane databases to identify all the possible studies that assess the effect of hemodynamic monitoring on hospitalizations in HF patients. The main outcomes considered were the rate of HF hospitalization, mortality, quality of life, and improvement in New York Heart Association (NYHA) functional class in the monitored group. Seven studies met all the eligibility criteria and were incorporated in our systematic review. Out of the seven studies we reviewed, three studies inserted the sensor in the pulmonary artery, three in the right ventricle, and only one in the left atrium. On an average, the single study on the left atrium showed the highest reduction (59.0\%) in HF hospitalization followed by the pulmonary artery (56.3\%) and right ventricle (31.0\%), respectively. Our systematic review demonstrates that the use of hemodynamic sensors in HF patients helps to reduce HF-related hospitalizations. Therefore, a combination of outpatient monitoring via the use of hemodynamic sensors and fluid management is needed to reduce HF hospitalizations and improve outcomes in HF patients.

Categories: Internal Medicine, Cardiology, Healthcare Technology

Keywords: heart failure, implantable hemodynamic sensors, hospitalization

Received 03/27/2017

Review began 04/05/2017

Review ended 04/05/2017

Published 04/13/2017

C) Copyright 2017

Minhas et al. This is an open access article distributed under the terms of the Creative Commons Attribution License CC-BY 3.0., which permits unrestricted use, distribution, and reproduction in any medium, provided the original author and source are credited.

\section{Introduction And Background}

Heart failure (HF) is the most frequent cause of hospitalization in people over the age of 65 with over one million admissions per year [1]. HF is a pressing health concern as the expense of hospitalization financially burdens the health care system. Around $70 \%$ of all direct and indirect costs created by HF patients are due to hospitalization and approximately $\$ 39.2$ billion was spent on care for patients with HF in the United States in 2010 [2-3]. The persistently high hospital readmission rates and prevalence for HF call for further improvements to current care approaches [4].

Several treatment strategies have been employed and tested in randomized clinical trials for early detection of the worsening of symptoms in HF patients. These strategies include 
telemonitoring, home weight monitoring, thoracic impedance, and remote monitoring [5-8]. Although these parameters have been shown to improve outcomes, they have failed to demonstrate an effect on re-hospitalizations in patients with HF [9-11]. Therefore, new management strategies are needed.

More than $90 \%$ of hospitalizations in decompensated HF are due to congestion, suggesting that monitoring for congestion is vital in the long-term management of HF [12]. Relying solely on symptoms and physical findings of volume overload has proven ineffective in avoiding HFrelated hospitalizations, as these are usually late manifestations of decompensated HF when the filling pressures are already substantially high and hospital admission is unavoidable. On the other hand, hemodynamic monitoring has the potential to detect increases in intracardiac filling pressures weeks before clinical deterioration because of the close relationship between volume and pressure in association with impaired volume regulation.

Implantable devices to monitor the cardiopulmonary filling pressures have been developed which focus on the pathophysiology of underlying HF [10, 13-18]. Hence, preliminary findings of volume overload with the use of these devices may prevent the progression of disease leading to a reduction in HF-associated hospitalizations. This management strategy has been tested in a variety of clinical trials. The aim of this systematic review is to establish, using these completed trials, whether hemodynamic monitoring using implantable sensors prevents HF hospitalizations and readmissions without causing any obvious safety concerns.

\section{Review}

An extensive literature search of PubMed, Embase, Medline, and Cochrane library were done using the keywords "hemodynamic monitoring" AND "hospitalization" AND "heart failure" OR "pulmonary artery" OR "right ventricle" OR "left atrium". The search was conducted from the inception of these databases until November 2016. Only articles written in English and published in peer-reviewed journals were included. Additional relevant articles were found by scrutiny of the bibliographies of the articles found in the search. Experts in the field were contacted to identify anything missed by the search.

All articles assessing the effect of hemodynamic monitoring on the hospitalizations in HF patients were considered. There was no restriction on the sample size, mean follow-up time, or type of study. Both types of studies, with and without a control group, were included. Eligible studies included patients with New York Heart Association (NYHA) Functional Class II, III and IV HF, regardless of the left ventricular ejection fraction. The main outcomes considered were the rate of HF-hospitalization, mortality, quality of life, and improvement in NYHA symptom class in the monitored group.

Firstly, the titles and abstracts of all the retrieved articles were reviewed by two authors. Full texts of the articles that met the eligibility criteria were extracted. These articles were then independently reviewed by the two authors. Discrepancies regarding the eligibility of the studies were resolved by consensus. A third author was contacted in situations where these discrepancies could not be resolved. The detailed search strategy is outlined using the Preferred Reporting Items for Systematic Reviews and Meta-Analyses (PRISMA) flow sheet in Figure 1. 


\section{Cureus}

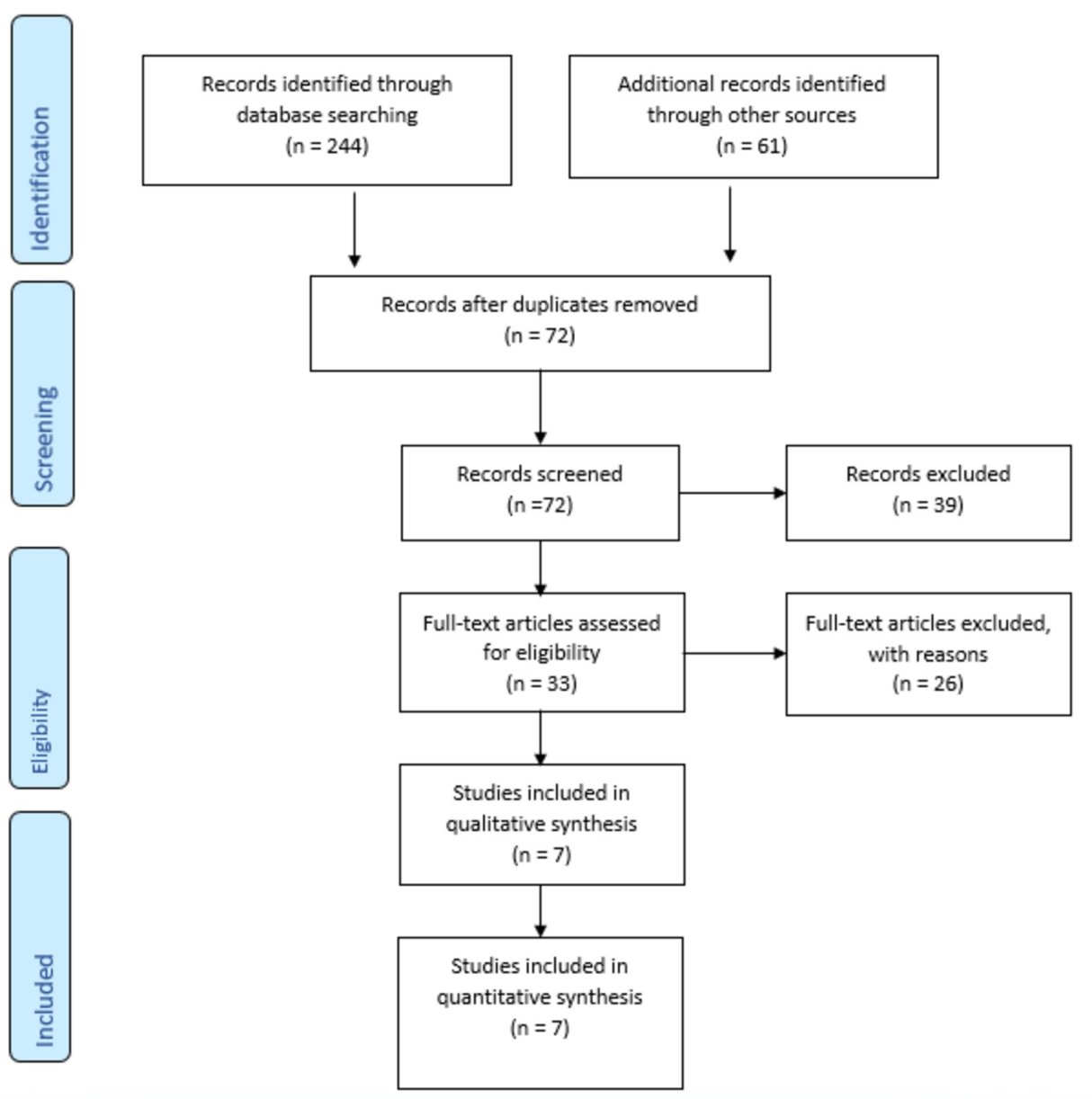

\section{FIGURE 1: PRISMA Flow Sheet}

PRISMA: Preferred Reporting Items for Systematic Reviews and Meta-Analyses

From the selected articles, descriptive information including the authors' names, patient demographics, medical treatment, NYHA Class, outcomes, and methodology were collected. Any disagreement between the two authors over the risk of bias in the included studies was resolved by discussion or by consulting a third author. The details of the methodology involved in each trial were important for efficient comparison of the studies and interpretation of results. Handling of the competing outcomes of HF-hospitalization by the authors was assessed. The authors of the included trials were contacted whenever any data needed clarification or any additional information was required.

Seven studies met all the eligibility criteria and were incorporated in our systematic review. Baseline characteristics of the included articles are shown in Table 1. All the studies were conducted in the USA; however, one study was multicentric across Australia, New Zealand, and the USA [12]. All the included studies were prospective in nature and the majority $(\mathrm{n}=4)$ of them were randomized controlled trials (RCTs). Five out of seven studies had a control group. The number of participants ranged from 32 to 550 and were predominantly older, averaging around 60 years of age overall. Around two-thirds of the patient populations in all the included studies were male, except one [18]. All the studies included patients that had some residual symptoms of HF (NYHA Class II-IV). 


\section{Cureus}

\begin{tabular}{|c|c|c|c|c|c|c|c|c|}
\hline $\begin{array}{l}\text { Serial } \\
\#\end{array}$ & $\begin{array}{l}\text { First } \\
\text { author, } \\
\text { year }\end{array}$ & Study design & Location & $\begin{array}{l}\text { Total } \\
\text { number of } \\
\text { subjects } \\
\text { (N) }\end{array}$ & $\begin{array}{l}\text { I and } \\
\mathrm{C}: \mathrm{N}=\end{array}$ & Age (I/C) & $\begin{array}{l}\text { Percentage } \\
\text { of males } \\
(\mathrm{I} / \mathrm{C} ; \%)\end{array}$ & NYHA Class \\
\hline 1. & $\begin{array}{l}\text { Bourge, } \\
2008[10]\end{array}$ & $\begin{array}{l}\text { Prospective, single- } \\
\text { blind, parallel, RCT trial }\end{array}$ & US & 274 & $\begin{array}{l}{[l]} \\
N=134 \\
{[C]} \\
N=140\end{array}$ & $58 \pm 14 / 58 \pm 13$ & 66/64 & III-IV \\
\hline 2. & $\begin{array}{l}\text { Ritzema, } \\
2010 \text { [12] }\end{array}$ & $\begin{array}{l}\text { Prospective, } \\
\text { observational, open- } \\
\text { label. }\end{array}$ & $\begin{array}{l}\text { US/ } \\
\text { Australia, } \\
\text { New } \\
\text { Zealand }\end{array}$ & 40 & $\begin{array}{l}\text { [I] } \mathrm{N}=40 \\
{[\mathrm{C}] \mathrm{N}=0}\end{array}$ & $66 \pm 10$ & $78 / 0$ & III \\
\hline 3. & $\begin{array}{l}\text { Adamson, } \\
2003 \text { [18] }\end{array}$ & $\begin{array}{l}\text { Prospective, } \\
\text { observational, historic } \\
\text { control. }\end{array}$ & US & 32 & $\begin{array}{l}{[1] \mathrm{N}=32} \\
{[\mathrm{C}] \mathrm{N}=0}\end{array}$ & $59 \pm 10$ & $38 / 0$ & II-III \\
\hline 4. & $\begin{array}{l}\text { Jermyn, } \\
2016[19]\end{array}$ & $\begin{array}{l}\text { Prospective, case } \\
\text { series with comparison } \\
\text { to concomitant control. }\end{array}$ & US & 66 & $\begin{array}{l}{[\mathrm{l}] \mathrm{N}=34} \\
{[\mathrm{C}]} \\
\mathrm{N}=32\end{array}$ & & $76 / 59$ & III \\
\hline 5. & $\begin{array}{l}\text { Adamson, } \\
2011[20]\end{array}$ & $\begin{array}{l}\text { Prospective, single- } \\
\text { blind, RCT. }\end{array}$ & US & 400 & $\begin{array}{l}\text { [l] } \\
\mathrm{N}=202 \\
{[\mathrm{C}]} \\
\mathrm{N}=198\end{array}$ & $55 \pm 15 / 55 \pm 15$ & $70 / 67$ & II-III \\
\hline 6. & $\begin{array}{l}\text { Abraham, } \\
2011 \text { [21] }\end{array}$ & $\begin{array}{l}\text { Prospective, single- } \\
\text { blind, RCT. }\end{array}$ & US & 550 & $\begin{array}{l}{[l]} \\
N=270 \\
{[C]} \\
N=280\end{array}$ & $61 \pm 13 / 62 \pm 13$ & $72 / 73$ & III \\
\hline 7. & $\begin{array}{l}\text { Abraham, } \\
2016 \text { [22] }\end{array}$ & $\begin{array}{l}\text { Prospective, single- } \\
\text { blind, RCT. }\end{array}$ & US & 550 & $\begin{array}{l}\mathrm{N}=270 \\
{[\mathrm{C}]} \\
\mathrm{N}=280\end{array}$ & $61.3 \pm 13 / 61 \cdot 8$ & $72 / 73$ & III \\
\hline
\end{tabular}

\section{TABLE 1: Characteristics of the Included Studies}

I: Intervention group; C: Control group; NYHA: New York Heart Association; US: United States; RCT: random controlled trials

The primary outcome assessed in all the studies was the rate of HF-related hospitalizations (Table 2). The duration of mean follow-up ranged from six to 25 months overall. The devices used included an implantable left atrial pressure (LAP) monitoring system, implanted right ventricle (RV) intracardiac continuous hemodynamic monitor, and CardioMEMS ${ }^{\text {тм }}$ Heart Sensor (St. Jude Medical, Inc, Atlanta, GA). The study by Jermyn, et al. [19] showed the highest reduction in hospitalizations (84\%), whereas the study by Adamson, et al. [20] showed no reduction in the number of hospitalizations $(0.004 \%)$. Two studies $[12,18]$ showed more than a $50 \%$ reduction while the remaining studies $[10,21-22]$ were less than $50 \%$. 


\section{Cureus}

\begin{tabular}{|c|c|c|c|c|c|c|}
\hline $\begin{array}{l}\text { Serial } \\
\#\end{array}$ & $\begin{array}{l}\text { First } \\
\text { author, } \\
\text { year }\end{array}$ & $\begin{array}{l}\mathrm{N}=\text { Intervention } \\
\text { group [I] and } \\
\text { Control-group [C] }\end{array}$ & Device used & $\begin{array}{l}\text { Mean } \\
\text { follow-up } \\
\text { (months) }\end{array}$ & $\begin{array}{l}\text { Reductions in HF } \\
\text { hospitalizations } \\
(\%)\end{array}$ & $\begin{array}{l}\mathrm{p}- \\
\text { value }\end{array}$ \\
\hline 1. & $\begin{array}{l}\text { Ritzema, } \\
2010[12]\end{array}$ & [l] $\mathrm{N}=40,[\mathrm{C}] \mathrm{N}=0$ & $\begin{array}{l}\text { Implantable LAP monitoring } \\
\text { system }\end{array}$ & 25 & 59.0 & 0.041 \\
\hline 2. & $\begin{array}{l}\text { Abraham, } \\
2011[21]\end{array}$ & [l] $\mathrm{N}=270,[\mathrm{C}] \mathrm{N}=\mathbf{2 8 0}$ & CardioMEMS ${ }^{\mathrm{TM}}$ Heart Sensor & 15 & 37.0 & \\
\hline 3. & $\begin{array}{l}\text { Adamson, } \\
2003 \text { [18] }\end{array}$ & [l] $\mathrm{N}=32,[\mathrm{C}] \mathrm{N}=0$ & $\begin{array}{l}\text { Implanted RV intracardiac } \\
\text { continuous hemodynamic } \\
\text { monitor }\end{array}$ & 17 & 57.0 & $<0.01$ \\
\hline 4. & $\begin{array}{l}\text { Bourge, } \\
2008 \text { [10] }\end{array}$ & [l] $\mathrm{N}=134,[\mathrm{C}] \mathrm{N}=140$ & $\begin{array}{l}\text { Implanted RV intracardiac } \\
\text { continuous hemodynamic } \\
\text { monitor }\end{array}$ & 6 & 36.0 & 0.03 \\
\hline 5. & $\begin{array}{l}\text { Adamson, } \\
2011 \text { [20] }\end{array}$ & [l] $\mathrm{N}=202,[\mathrm{C}] \mathrm{N}=198$ & $\begin{array}{l}\text { Implanted ICD with RV } \\
\text { intracardiac continuous } \\
\text { hemodynamic sensor }\end{array}$ & 12 & 0.004 & \\
\hline 6. & $\begin{array}{l}\text { Jermyn, } \\
2016 \text { [19] }\end{array}$ & {$[1] \mathrm{N}=34,[\mathrm{C}] \mathrm{N}=32$} & CardioMEMS ${ }^{\mathrm{TM}}$ Heart Sensor & 15 & 84.0 & \\
\hline 7. & $\begin{array}{l}\text { Abraham, } \\
2016 \text { [22] }\end{array}$ & [I] N=270 [C] N=280 & CardioMEMS $^{\mathrm{TM}}$ Heart Sensor & 13 & 48.0 & $\begin{array}{l}< \\
0.0001\end{array}$ \\
\hline
\end{tabular}

\section{TABLE 2: Effectiveness of Hemodynamic Sensors in Reducing Hospital}

Readmissions in Patients with Chronic Heart Failure

HF: heart failure; I: Intervention group; C: Control group; LAP: left atrial pressure; RV: right ventricle; ICD: implantable cardioverterdefibrillator

Table 3 illustrates the differences in the rate of hospitalizations according to the location of the devices. Out of the seven studies we reviewed, three studies inserted the sensor in the pulmonary artery, three in the right ventricle, and only one in the left atrium. On an average, the single study on the left atrium showed the highest reduction (59.0\%), followed by the pulmonary artery (56.3\%) and right ventricle (31.0\%), respectively. No major pressure sensor failures were reported by any of the included studies. 


\section{Cureus}

\begin{tabular}{|l|l|l|l|}
\hline Location of device & First author, year & Reductions in HF hospitalizations (\%) & Mean reduction (\%) \\
\hline & Abraham, 2011 [21] & 37.0 & \\
Pulmonary artery & Jermyn, 2016 [19] & 84.0 & 56.3 \\
& Abraham, 2016 [22] & 48.0 & \\
& Adamson, 2003 [18] & 57.0 & 31.0 \\
Right ventricle & Bourge, 2008 [10] & 36.0 & \\
\hline Left atrium & Adamson, 2011 [20] & 0.004 & 59.0 \\
\hline
\end{tabular}

\section{TABLE 3: Differences in Rates of Hospitalization According to the Location of the}

Device

HF: heart failure

In this systematic review, we observed that the use of hemodynamic sensors in HF patients lowers the rate of HF hospitalizations when compared to usual care. These trials included devices that measure pulmonary artery pressure, right ventricular pressure, and left atrial pressure. The studies were in congruence that monitoring filling pressures aids in avoiding exacerbations of $\mathrm{HF}$ that lead to hospitalizations; two studies reported that the filling pressures in patients experiencing an $\mathrm{HF}$ event were significantly elevated regardless of treatment group $(p<0.001)[20]$ and that there was an increase in the pressure 24 hours before hospitalization [18]. These findings are in harmony with previously published research [23-26].

Jermyn, et al. reported the highest rate of reduction in HF-hospitalizations (84\%) among all seven studies. This study used the patients in the monitored group as their own controls by comparing their rates of hospitalizations in the year prior to the implantation of the sensor [19]. Comparing the same patient population before and after implantation may be more effective as the severity of underlying HF or various co-morbidities vary in different sets of patients and may alter the results. The results of this study may also have been exaggerated due to a small sample size. On the contrary, Adamson, et al. reported no reduction in the rate of HF hospitalization in the 12 months of follow-up [20]. However, this study was terminated earlier than planned during early enrollment as a device failure was observed in the patients from previous trials that used the same pressure sensing lead. Early enrollment termination and the defective pressure sensing lead may have undermined the results of the trial.

Along with reducing the rate of HF events, Abraham, et al. found a significant decrease in the length of HF hospitalizations ( $p=0.02$ ) with the use of hemodynamic monitoring [21]. Furthermore, Abraham, et al. and Ritzema, et al. found an improvement in the quality of life and mortality in patients receiving hemodynamic care $[12,21]$. On the other hand, another study reported no significant reduction in the rate of mortality in these patients $(p=0.23)$ [22]. NYHA symptom class improved significantly in the study by Jermyn, et al. $(\mathrm{p}<0.0001)$ [21]. Further assessment on the effect of hemodynamic sensors on the quality of life and mortality is imperative and recommended. 
Bourge, et al. observed a lower than expected event rate in the control group [10]. This was attributed to the fact that regular patient contact with HF management teams reduces hospitalizations as suggested by previous research [27-28]. Therefore, a combination of hemodynamic monitoring via sensor implantation with frequent patient contact with the HF management team may optimize the outcomes in HF-related hospitalizations. Furthermore, Bourge, et al. reported that there was no increase in HF events because of over-diuresis; one of the major feared complications of using hemodynamic sensors. Ritzema, et al., who observed that awareness of pressure trends leads to a better compliance with prescriptions and appropriate diuretic dosing [12], supported this. Due to the association of high diuretic intake and poor HF outcomes, this may contribute to better outcomes and a decrease in the rate of HF hospitalization.

Several limitations in this review need to be considered. Our search was limited to articles in English and electronic databases which may have led to a language and publication bias and some pertinent articles not being included in the review. Our study may be affected by a population bias as all the trials were conducted in Western countries. The mean follow-up times for all the studies were different; the long-term effectiveness of these sensors may not have been assessed properly in those with a shorter follow-up time. The trials made use of different devices, and the individual efficacy of the devices may have affected the results of individual trials.

\section{Conclusions}

The use of hemodynamic sensors in HF patients helps to reduce HF-related hospitalizations. Hemodynamic information is vital because patients, in whom filling pressures are increasing, are at a high risk of hospitalization. Therefore, a combination of outpatient monitoring via the use of hemodynamic sensors and fluid management is needed to reduce HF hospitalizations and improve outcomes in HF patients.

\section{Additional Information Disclosures}

Conflicts of interest: In compliance with the ICMJE uniform disclosure form, all authors declare the following: Payment/services info: All authors have declared that no financial support was received from any organization for the submitted work. Financial relationships: All authors have declared that they have no financial relationships at present or within the previous three years with any organizations that might have an interest in the submitted work. Other relationships: All authors have declared that there are no other relationships or activities that could appear to have influenced the submitted work.

\section{References}

1. Desai AS, Stevenson LW: Rehospitalization for heart failure: predict or prevent? . Circulation. 2012, 126:501-6. 10.1161/CIRCULATIONAHA.112.125435

2. Dickstein K, Cohen-Solal A, Filippatos G, et al.: ESC guidelines for the diagnosis and treatment of acute and chronic heart failure 2008: the Task Force for the Diagnosis and Treatment of Acute and Chronic Heart heart failure 2008 of the European Society of Cardiology. Developed in collaboration with the Heart Failure Association of the ESC (HFA) and endorsed by the European Society of Intensive Care Medicine (ESICM). Eur J Heart Fail. 2008, 10:933-89. 10.1016/j.ejheart.2008.08.005

3. Lloyd-Jones D, Adams RJ, Brown TM, et al.: Heart disease and stroke statistics-2010 update A report from the American Heart Association. Circulation. 2010, 121:e46-e215.

10.1161/CIRCULATIONAHA.109.192667

4. Gheorghiade M, Vaduganathan M, Fonarow GC, Bonow RO: Rehospitalization for heart 
failure: problems and perspectives. J Am Coll Cardiol. 2013, 61:391-403.

10.1016/j.jacc.2012.09.038

5. Chaudhry SI, Mattera JA, Curtis JP, et al.: Telemonitoring in patients with heart failure . N Engl J Med. 2010, 363:2301-9. 10.1056/NEJMoa1010029

6. Koehler F, Winkler S, Schieber M, et al.: Impact of remote telemedical management on mortality and hospitalizations in ambulatory patients with chronic heart failure: the telemedical interventional monitoring in heart failure study. Circulation. 2011, 123:1873-80. 10.1161/CIRCULATIONAHA.111.018473

7. van Veldhuisen DJ, Braunschweig F, Conraads V, et al.: Intrathoracic impedance monitoring, audible patient alerts, and outcome in patients with heart failure. Circulation. 2011, 124:1719-26. 10.1161/CIRCULATIONAHA.111.043042

8. Böhm M, Drexler H, Oswald H, et al.: Fluid status telemedicine alerts for heart failure: a randomized controlled trial. Eur Heart J. 2016, 37:3154-63. 10.1093/eurheartj/ehw099

9. Clark RA, Inglis SC, McAlister FA, et al.: Telemonitoring or structured telephone support programmes for patients with chronic heart failure: systematic review and meta-analysis. BMJ. 2007, 334:942. 10.1136/bmj.39156.536968.55

10. Bourge RC, Abraham WT, Adamson PB, et al.: Randomized controlled trial of an implantable continuous hemodynamic monitor in patients with advanced heart failure: the COMPASS-HF study. J Am Coll Cardiol. 2008, 51:1073-79. 10.1016/j.jacc.2007.10.061

11. Pandor A, Gomersall T, Stevens JW, et al.: Remote monitoring after recent hospital discharge in patients with heart failure: a systematic review and network meta-analysis. Heart. 2013, 99:1717-26. 10.1136/heartjnl-2013-303811

12. Ritzema J, Troughton R, Melton I, et al.: Physician-directed patient self-management of left atrial pressure in advanced chronic heart failure. Circulation. 2010, 121:1086-95. 10.1161/CIRCULATIONAHA.108.800490

13. Magalski A, Adamson P, Gadler F, et al.: Continuous ambulatory right heart pressure measurements with an implantable hemodynamic monitor: a multicenter, 12-month followup study of patients with chronic heart failure. J Card Fail. 2002, 8:63-70.

10.1054/jcaf.2002.32373

14. Verdejo HE, Castro PF, Concepción R, et al.: Comparison of a radiofrequency-based wireless pressure sensor to Swan-Ganz catheter and echocardiography for ambulatory assessment of pulmonary artery pressure in heart failure. J Am Coll Cardiol. 2007, 50:2375-82. 10.1016/j.jacc.2007.06.061

15. Castro PF, Concepción R, Bourge RC, et al.: A wireless pressure sensor for monitoring pulmonary artery pressure in advanced heart failure: initial experience. J Heart Lung Transplant. 2007, 26:85-88. 10.1016/j.healun.2006.10.006

16. Ritzema J, Melton IC, Richards AM, et al.: Direct left atrial pressure monitoring in ambulatory heart failure patients: initial experience with a new permanent implantable device. Circulation. 2007, 116:2952-59. 10.1161/CIRCULATIONAHA.107.702191

17. Zile MR, Bennett TD, St John Sutton M, et al.: Transition from chronic compensated to acute decompensated heart failure: pathophysiological insights obtained from continuous monitoring of intracardiac pressures. Circulation. 2008, 118:1433-41. 10.1161/CIRCULATIONAHA.108.783910

18. Adamson PB, Magalski A, Braunschweig F, et al.: Ongoing right ventricular hemodynamics in heart failure: clinical value of measurements derived from an implantable monitoring system. J Am Coll Cardiol. 2003, 41:565-71. 10.1016/S0735-1097(02)02896-6

19. Jermyn R, Alam A, Kvasic J, et al.: Hemodynamic-guided heart-failure management using a wireless implantable sensor: Infrastructure, methods, and results in a community heart failure disease-management program. Clin Cardiol. 2017, 40:170-76. 10.1002/clc.22643

20. Adamson PB, Gold MR, Bennett T, et al.: Continuous hemodynamic monitoring in patients with mild to moderate heart failure: results of The Reducing Decompensation Events Utilizing Intracardiac Pressures in Patients With Chronic Heart Failure (REDUCEhf) trial.. Congest Heart Fail. 2011, 17:248-54. 10.1111/j.1751-7133.2011.00247.x

21. Abraham WT, Adamson PB, Bourge RC, et al.: Wireless pulmonary artery haemodynamic monitoring in chronic heart failure: a randomised controlled trial. Lancet. 2011, 377:658-66. 10.1016/S0140-6736(11)60101-3

22. Abraham WT, Stevenson LW, Bourge RC, et al.: Sustained efficacy of pulmonary artery pressure to guide adjustment of chronic heart failure therapy: complete follow-up results 


\section{Cureus}

from the CHAMPION randomised trial. Lancet. 2016, 387:453-61. 10.1016/S0140-

6736(15)00723-0

23. Stevenson LW, Zile M, Bennett TD, et al.: Chronic ambulatory intracardiac pressures and future heart failure events. Circ Heart Fail. 2010, 3:580-87.

10.1161/CIRCHEARTFAILURE.109.923300

24. Zile MR, Bennett TD, St John Sutton M, et al.: Transition from chronic compensated to acute decompensated HF: pathophysiological insights obtained from continuous monitoring of intracardiac pressures. Circulation. 2008, 118:1433-41.

10.1161/CIRCULATIONAHA.108.783910

25. Zile MR, Adamson PB, Cho YK, et al.: Hemodynamic factors associated with acute decompensated heart failure: part 1--insights into pathophysiology. J Card Fail. 2011, 17:28291. 10.1016/j.cardfail.2011.01.010

26. Adamson PB, Zile MR, Cho YK, et al.: Hemodynamic factors associated with acute decompensated HF: part 2-Use in automated detection. J Card Fail. 2011, 17:366-73.

10.1016/j.cardfail.2011.01.011

27. Ducharme A, Doyon O, White M, et al.: Impact of care at a multidisciplinary congestive heart failure clinic: a randomized trial. CMAJ. 2005, 173:40-45. 10.1503/cmaj.1041137

28. McAlister FA, Stewart S, Ferrua S, McMurray JJ: Multidisciplinary strategies for the management of heart failure patients at high risk for admission: a systematic review of randomized trials. J Am Coll Cardiol. 2004, 44:810-9. 10.1016/j.jacc.2004.05.055 